\title{
MANAJEMEN KURIKULUM MADRASAH SEBAGAI UPAYA PENINGKATAN MUTU PENDIDIKAN
}

\author{
Khoirunnisaa' \\ Sekolah Tinggi Agama Islam (STAI) Madiun \\ ns_khoir@yahoo.co.id
}

\section{Abstrak}

All efforts undertaken by the school to obtain the expected results make the understanding of the curriculum tend to be broad, because in situations inside and outside the school, or as a number of potential experiences that can be provided by the school with the aim that children and youth are accustomed to thinking and acting according the group or community where be lives. The curriculum must always be changed because of changes in society due to advances in science and technology. Curriculum changes must be continuous so that they are not obsolete and out of date. Each teacher must determine their own interpretation. Because there are various definitions about the curriculum,. His choice will affect his conception of his duty as an educator. He can embrace a traditional stance, that is, which adheres to a curriculum based on subjects or subjects that are usually given separately, or progressively, that is, studying science to solve problems. Some specific ways of practicing curriculum change are (1) pilot projects (2) developing cadres (3) utilizing teachers who have mastered new ways (4) providing teaching tools (5) updating textbooks (6) collaboration between schools and universities (7) curriculum renewal of teacher education (8) demonstrates an update (9) initiates renewal with unit lessons. Each curriculum has the following four components: (1) objectives (2) knowledge (3) learning experience activities (4) assessors. The four components are interconnected. Curriculum changes 
are often a reaction to the existing curriculum. In renewing the curriculum it should be utilized as much as possible the benefits of other curriculum forms.

Kata Kunci: Kurikulum, Mutu pendidikan, Madrasah

\section{A. PENDAHULUAN}

Kurikulum secara praktik maupun teori kurikulum yang lama sudah banyak ditinggalkan karena sudah tidak sesuai dengan perkembangan ilmu dan teknologi yang juga selalu berkembang. Kurikulum banyak mengalami perkembangan karena pemikiran yang banyak oleh tokoh-tokoh mengenai kurikulum. Kurikulum yang semula berarti jarak yang harus ditempuh, kemudian menjadi sejumlah mata pelajaran yang harus dilalui untuk mendapat ijazah

Para ahli kurikulum "modern" cenderung memberikan pengertian yang lebih luas, sehingga meliputi kegiatan di luar kelas, bahkan juga mencakup segala sesuatu yang dapat mempengaruhi kelakuan siswa, termasuk kebersihan kelas, pribadi guru, sikap petugas sekolah, dan lain-lain.

Kurikulum adalah sesuatu yang direncanakan sebagai pegangan guna mencapai tujuan pendidikan. Tafsiran kurikulum dapat dipandang dari berbagai segi, yakni, curriculum as a product bisa dituangkan dalam bentuk buku atau pedoman kurikulum, as a program terwujud dalam perkumpulan sekolah, pertandingan, pramuka, warung sekolah dan lain-lain, as intended learning seperti pengetahuan, sikap, dan ketrampilan tertentu, as the experiences of the learner yaitu apa yang diwujudkan pada diri anak berbeda dengan apa yang diharapkan. Dapat pula kita memandangnya sebagai formal curriculum, ideal real, actual curriculum atau potensial learning experiences.

Dalam tulisan M. Arif Khoirudin tentang manajemen kurikulum sedikitnya ada 5 prinsip ${ }^{1}$ yang harus menjadi perhatian penting, yaitu: produktivitas, demokratisasi, kooperatif, efektivitas dan efisiensi, mengarahkan visi, misi, tujuan yang ditetapkan dalam kurikulum. ${ }^{2}$

Kajian teori manajemen kurikulum yang ditulis oleh Ibrahim $\mathrm{Nasbi}^{3}$ ber-

${ }^{1}$ Sanjaya, Kurikulum dan Pembelajaran: Teori \& Praktek KTSP, (Jakarta: Kencana, 2009), hlm. 128

2 M. Arif Khoirudin, "Manajemen Kurikulum Dalam Meningkatkan Mutu Pendidikan." Tribakti: Jurnal Pemikiran Islam 24, no. 1 (Januari 2013). dalam https://ejournal.iai-tribakti. ac.id/index.php/tribakti/article/view/126/118

3 Ibrahim Nasbi. "Manajemen Kurikulum: Sebuah Kajian Teoritis." Jurnal IDAARAH I, no. 2 (Desember 2017), dalam http://journal.uin-alauddin.ac.id/index.php/idaarah/article/ viewFile/4274/3936 
isi tentang prinsip-prinsip manajemen seperti yang diuraikan oleh M. Arif Khoirudin.

Dari kedua tulisan tersebut maka dalam pembahasan berikut akan menguraikan tentang komponen - komponen kurikulum dalam manajemen pendidikan, Perubahan dan perbaikan kurikulum, kurikulum dan masyarakat, organisasai kurikulum, menentukan scope dan squence dan mengubah kurikulum.

\section{B. PENGERTIAN KURIKULUM}

\section{Pengertian Kurikulum}

Pengertian kurikulum yang terlampau luas atau terlampau sempit mengandung unsur kebaikan dan kelemahan. Hilda Taba termasuk yang memberi pengertian kurikulum bahwa pada hakikatnya kurikulum merupakan suatu cara untuk mempersiapkan anak agar berpartisipasi sebagai anggota yang produktif dalam masyarakatnya atau memandang kurikulum sebagai "a plain for learning".

\section{Komponen-komponen kurikulum.}

Komponen komponen kurikulum ada empat seperti pada gambar berikut:

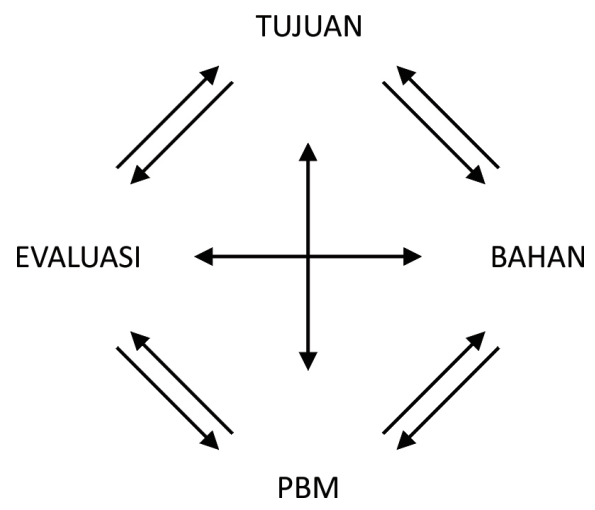

Komponen-komponen itu antara lain: (1) tuuan, (2) bahan pelajaran, (3) proses belajar-mengajar, (4) evaluasi atau penilaian. Keempat komponen itu saling berhubungan dan bertalian erat satu sama lainnya. Tujuan menentukan bahan apa yang akan dipelajari, bagaimana proses belajarnya, dan apa yang harus dinilai. Demikian pula penilaian dapat mempengaruhi komponen 
lainnya.. kalau tujuannya jelas, maka bahan pelajaran, PBM, maupun evaluasinya pun lebih jelas.

Asas-asas yang mendasari setiap kurikulum ada empat, yaitu:

a. Asas filosofis yang berkenaan dengan tujuan pendidikan yang sesuai dengan filsafat Negara.

b. Asas psikologis yang memperhitungkan faktor anak dalam kurikulum yakni: a. psikologi anak, perkembangan anak, b. psikologi belajar, bagaimana proses belajar anak.

c. Asas sosiologis, yaitu keadaan masyarakat, perkembangan dan perubahannya, kebudayaan manusia, hasil kerja manusia berupa pengetahuan, dan lain-lain. Tuntutan masyarakat tidak dapat diabaikan karena dengan penuh rasa tanggung jawab menerima jasa dari masyarakat dan sebaliknya harus menyumbangkan baktinya bagi kemajuan masyarakat. Perubahan masyarakat akibat perkembangan ilmu pengetahuan dan teknologi merupakan factor pertimbanagn dalam kurikulum selain norma-norma, adat kebiasaan yang nantinya akan terwujud dalam kepribadian anak.

d. Asas organisatoris yang mempertimbangkan bentuk dan organisasi bahan pelajaran yang disajikan. Apakah dalam bentuk mata pelajaran yang terpisah-pisah, ataukah diusahakan adanya hubungan antara pelajaran yang diberikan. Jadi dalam bentiuk kurikulum yang terpadu. ${ }^{4}$

\section{PROSES PERUBAHAN DAN PERBAIKAN KURIKULUM}

Perubahan kurikulum adalah perubahan sosial, curriculum change is social change. Perubahan adalah pergeseran posisi, kedudukan atau keadaan. Sedangkan perbaikan sering dikaitkan dengan penilaian dan dilaksanakan untuk meningkatkan nilai dan untuk mengetahuinya digunakan kriteria tertentu. Sehingga kurikulum harus bersifat antisipatif dan adaptif (mampu menyesuaikan diri) terhadap perubahan masyarakat itu sehingga kurikulum dituntut dinamis mengikuti perkembangan masyarakat dan ilmu pengetahuan dan cenderung mengalami perubahan dan perbaikan bahkan pembaharuan terus menerus. ${ }^{5}$

${ }^{4}$ S. Nasution, Asas-asas kurikulum, Edisi kedua,Jakarta: Bumi Aksara, 2003, hlm. 11.

5 Muhammad Nurhalim, Analisis Perkembangan Kurikulum Di Indonesia, INSANIA: Jurnal Pemikiran Alternatif Pendidikan,(Purwokerto: IAIN Purwokerto) Vol. 16 No. 3, September- 
Menurut ahli sosiologi, perubahan terjadi dalam tiga fase, yaitu fase inisiasi yaitu taraf permulaan ide perubahan yang lancar dengan menjelaskan sifatnya,tujuan, dan luas perubahan yang ingin dicapai, fase legitimasi, saatnya orang menerima ide, dan fase kongruensi, mengadopsinya dengan menyamakan pendapat sehingga selaras dengan pikiran para pencetus, sehingga tidak terdapat perbedaan nilai lagi antara penerima dan pencetus perubahan.

Perubahan akan lebih berhasil bila dari pihak guru dalam keadaan kekurangan, sehingga timbul hasrat untuk memperbaikinya demi kepentingan bersama.

Guru yang konservatif sangat sulit menerima perubahan. Namun ketika merasa tidak puas dengan keadaan maka ia akanmencari sesuatu yang baru. Oleh karena itu yang bisa mengetahui kebutuhan guru maka akan dengan mudah memproses perubahan misalnya memberi alternatif pengajaran.

Orang yang berperan mengubah kurikulum harus dapat mempengaruhi orang dan memberi inspirasi. Serta mempunyai sensitivitas sosial, terbuka bagi perubahan.

Menurut para ahli dalam"social engineering"dalam usaha mengadakan perubahan dapat dilalui empat langkah, yaitu menganalisis situasi, menentukan perubahan yang perlu diadakan, mengadakan perubahan itu, dan memantapkan perubahan itu. Perubahan hanya dapat berhasil bila semua kerja sama.

Sebab kelambanan kurikulum yaitu kurikulum belum cukup mempunyai dasar ilmiah, kurikulum tidak mempunyai petugas tertentu yang kapan saja bersedia memberi bantuan, guru atau siapa saja yang mengadakan perbaikan tidak mendapat insetif dan hanya menerima penghargaan finansial berupa gaji seperti guru yang lain yang hanya mengikuti tradisi, dan kebanyakan guru mempertahankan cara-cara lama yang telah teruji dan telah dikenalnya dengan baik dan dijalankan secara rutin.

Pengawasan yang terlampau ketat dari atasan akan menghambat berkembangnya inisiatif dan kreativitas guru dan merendahkannya menjadi sekedar tukang yang banyak kerja secara otomatis dan rutin, padahal mengajar itu selalu merupakan "adventure" penuh rahasia yang menarik untuk dipikirkan

Perubahan kurikulum ada empat yaitu (1) substitusi, dapat berupa mengganti buku pelajaran, (2) alterasi, perubahan dengan cara menambah atau mengurangi jam pelajaran, variasi metode, (3) restrukturisasi, (4) orientasi ni-

Desember 2011 dalam http://ejournal.iainpurwokerto.ac.id/index.php/insania/article/ view/1597 
lai-nilai baru. Selain itu perubahan kurikulum hendaknya menyesuaikan diri dengan kebudayaan.

Langkah-langkah dalam proses mengubah kurikulum yaitu (1) pupuklah suasana dan kondisi kerja yang serasi, (2) berikan waktu yang cukup, jangan terlampau cepat, jangan pula terlampau lambat, (3) tentukan kegiatan yang sesuai, (4) tentukan prosedur penilaian dalam tiap usaha perubahan.

Kurikulum yang uniform dapat menjadi alasan bagi guru untuk menjauhi inisiatif perbaikan dan hanya menunggu instruksi dari pihak atasan. Dasardasar pertimbangan agar usaha itu berhasil baik, antara lain (1) mengetahui tujuan perbaiakan, (2) mengenal situasi sekolah, (3) mengetahui kebutuhan siswa dan guru, (4) mengenal masalah yang dihadapi sekolah, (5) mengenal kompetensi guru, (6) mengetahui gejala sosial, (7) mengetahui perkembangan dan aliran dalam kurikulum.

Langkah-langkah pengembangan kurikulum yaitu: (1) adakan penilaian umum tentang sekolah, (2) selidiki berbagai kebutuhan, (3) mengidentifikasi masalah dan merumuskannya, (4) mengajukan saran perbaikan, (5) menyiapkan desain perencanaannya, (6) memilih anggota panitia, (7) mengawasi pekerjaan panitia, (8) melaksanakan hasil panitia oleh guru dalam kelas, (9) menerapkan cara-cara evaluasi,(10) memantapkan perbaikan. Perubahan kurikulum senantiasa melibatkan perubahan manusia yang melaksanakannya supaya kurikulum berubah demi perbaikan dan guru harus berubah bahkan didorong untuk berubah.

Dalam proses pengembangan kurikulum memerlukan partisipasi dari semua yang tiap hari terlibat dalam kurikulum yaitu guru, murid, kepala sekolah dan penilik sekolah sekolah dari kanwil.

Kurikulum yang bagus adalah kurikulum yang berusaha untuk mencapai tujuan dan berikut strategi-strategi yang bisa di gunakan yaitu (1) mengubah seluruh sistem pendidikan yang hanya dapat dilakukan oleh pusat karena berwenang penuh mengadakan perubahan kurikulum secara total, (2) mengubah kurikulum tingkat lokal, (3) memberikan pendidikan in-service dan pengembangan staf, (4) supervisi, (5) reorganisasi sekolah, (6) eksperimentasi dan penelitian

\section{KURIKULUM DAN MASYARAKAT}

Perubahan pada masyarakat akan berakibat juga pada perubahan pendidikan termasuk kurikulum. Salah satu ciri masyarakat ialah perubahannya yang cepat akibat perkembangan ilmu pengetahuan yang diterapkan dalam 
teknologi, yang sering tidak dapat diramalkan akibatnya.

Yang harus dipelajari oleh Pembina kurikulum adalah keadaaan, perkembangan, kegiatan, dan aspirasi masyarakat. Perubahan masyarakat mengharuskan kurikulum senantiasa ditinjau kembali. Kemajuan teknologi juga memperbesar kebergantungan manusia pada manusia yang lain.

Sekolah harus menyampaikan unsur-unsur yang berfaedah. Jadi fungsi sekolah dan kurikulum antara lain (1) mengawetkan kebudayaan, (2) memajukan masyarakat (agent of change), (3) merekonstruksi dan memperbaiki masyarakat, (4) mengubah tata-sosial, (5) management and control of social change dan as social engineering, and of educators statesman, (6) konservatif, (7) mengembangkan individu.

Sekolah yang bersifat konservatisme menyampaikan kultur atau kebudayaan kepada anak-anak. Sekolah menjadi lembaga sosial untuk mewujudkan tujuan-tujuan sosial dan alat utama agar generasi muda menerima cara hidup yang dianggap baik oleh masyarakat. Manfaatnya orang berhati-hati menerima pembaharuan-pembaharuan yang belum diuji dan dicobakan lebih dahulu dengan hasil yang memuaskan.

Disamping peranan konsevatisme sekolah mempunyai juga peranan evaluatif yaitu anak-anak tidak hanya menerima begitu saja apa yang mereka peroleh dari generasi yang lama tetapi harus mampu berpikir kritis, dan peranan kreatif yaitu tidak mematikan inisiatif dan kreativitas murid-murid.

Pembaharuan pengajaran harus dimulai dalam diri guru sendiri. Faktor lain yang menyebabkan sekolah bersifat konservatif adalah terletak dalam diri manusia itu sendiri. Salah satunya adalah mempertahankan tradisi.

Perubahan teknologi akhir-akhir ini sedikit banyak mempengaruhi cara hidup dan cara berpikir manusia.oleh karena itu sekolah harus mendidik untuk kehidupan. Dengan kurikulum yang senantiasa dapat berubah sesuai dengan perubahan masyarakat yaitu bersifat fleksibel. Kurikulum yang uniform mematikan inisiatif guru, mengekang kebebasannya dan menutup kemungkinan untuk menyesuaikan kurikulum dengan keadaan masyarakat dan kebutuhan murid-murid setempat.

Masyarakat sebagai sumber pelajaran berarti kurikulum tidak boleh lepas dari masyarakat. Untuk dapat membuat kurikulum yang berbasis masyarakat, maka perlu diselidiki sebagai berikut: keadaan fisis, penduduk,dan organisasi-organisasi masyarakat. Yaitu dengan cara mengadakan karyawisata atau field trip, menggunakan orang sebagai sumber, pengabdian masyarakat, dan pengalaman kerja dalam masyarakat. Bahan-bahan yang harus dikumpulkan 
oleh guru adalah informasi tentang keadaan alam, sejarah, penduduk, transpor dan perhubungan, kehidupan kekeluargaan, industri dan jabatan-jabatan, kesehatan, pendidikan, agama, rekreasi, pemerintahan, dan sebagainya. Kepada orang tua murid dan kepada orang-orang lain dapat dikirimkan daftar pertanyaan dalam bidang manakah mereka dapat bertindak sebagai sumber. Dan perusahaan-perusahaan juga dikirim daftar pertanyaan apakah mereka bersedia menerima murid-murid berkunjung ke sana dengan tujuan pendidikan. Jadi sekolah masyarakat sangat mengutamakan faktor masyarakat dalam kurikulumnya.

\section{E. ORGANISASI KURIKULUM}

Organisasi kurikulum yaitu pola atau bentuk bahan pelajaran disusun dan disampaikan kepada murid-murid. Tujuan-tujuan yang dicapai dengan proyek atau unit berlainan dengan apa yang dicapai dengan kurikulum berdasarkan matapelajaran yang terpisah-pisah. Organisasi kurikulum menentukan bahan pelajaran, urutannya dan cara menyajikannya.

Bentuk kurikulum yang lebih 'tua" dari yang lain adalah subject curriculum yang berpusat pada matapelajaran yang sendiri - sendiri. Sebagai reaksi terhadap apa yang dianggap kekurangan-kekurangan kurikulum ini timbul organisasi kurikulum yang lain seperti correlated curriculum dan integrated curriculum. Integrated curriculum dapat berbentuk activity curriculum, project curriculum atau experience curriculum, life curriculum atau core curriculum. ${ }^{6}$ Adapun faktor yang harus dipertimbangkan dalam organisasi kurikulum, yaitu: a) Ruang lingkup (Scope), b) Urutan (Sequence), c) Kesinambungan (Continuity), d) Terpadu (Integrated), e) Keseimbangan (Balance), f) Waktu (Times). Beberapa prosedur dalam mereorganisasi kurikulum dapat melalui: a) Mata pelajaran, b) Tambal sulam, c) Analisis kegiatan, d) Fungsi sosial, e) Survei pendapat, f) Studi kesalahan, g) Analisis masalah remaja. ${ }^{7}$

Subject curriculum telah ada sejak zaman Yunani yang dilanjutkan oleh orang Romawi dalam betuk trivium (gramatika, retorikam dan logika) dan quadrivium (arithmatika, geometri, astronomi dan musik), keduanya dikenal sebagai "the seven Liberal Arts".

6 S. Nasution, Asas-asas kurikulum, , hlm. 177

7 Aset Sugiana, Proses Pengembangan Organisasi Kurikulum dalam Meningkatkan Pendidikan di Indonesia Jurnal Pedagogik, Vol. 05 No. 02, Juli-Desember 2018 dalam https://ejournal.unuja.ac.id/index.php/pedagogik 
Pada abad pertengahan timbul matapelajaran yang vokasional (teologi, kedokteran, hukum) dan kini telah terdapat ratusan macam pelajaran,termasuk yang dianggap non-akademis.

Subject sebenarnya pengalaman umat manusia sepanjang masa yang disusun secara logis sistematis.

Manfaat subject curriculum yaitu: (1) bahan pelajaran dapat disajikan secara logis dan sistematis, (2) organisasi kurikulum ini sederhana, mudah dan direncanakan dan dilaksanakan, (3) kurikulum mudah dinilai, (4) kurikulum juga dipakai di pendidikan tinggi, (5) kurikulum telah dipakai berabad-abad lamanya dan sudah menjadi tradisi, (6) kurikulum lebih memudahkan guru, (7) kurikulum mudah diubah,(8) organisasi kurikulum yang sistematis esensial untuk menafsirkan pengalaman.

Setiap bentuk kurikulum mempunyai kebaikan dan kekurangan. Kekurangan-kekurangan suatu kurikulum sering ditonjolkan oleh para penentangnya ditinjau dari segi pendirian masing-masing.

Walaupun subject curriculum banyak dikecam, dan boleh dikatakan hampir tak ada yang memperjuangkannya, namun bentuk kurikulum masih sangat popular dimana-mana di dunia, terutama di Perguruan Tinggi.

Bentuk kurikulum yang lebih baru, yang juga banyak keuntungannya dan mempunyai cirri-ciri yang mengatasi kelemahan subject curriculum, namun tidak mendapat popularitas yang luas, anatara lain, karena tidak dapat memberikan pengathuan yang sistematis yang masih merupakan syarat bagi universitas dan arena tidak dipersiapkan untuk itu.

Metode yang diutamakan dalam integrated curriculum ialah metode "problem Solving" atau metode ilmiah dengan menghadapkan siswa kepada masalah-masalah yang bermakna baginya.

Menjalankan integrated curriculum tidak berarti menyampingkan subject sama sekali, melainkan memanfaatkannya secara fungsional dalam pemecahan masalah. Subject curriculum dapat mengatasi kelemahannya dengan memanfaatkan kebaikan-kebaikan bentuk kurikulum lainnya.

Core curriculum selalu mengenai pendidikan umum dapat diterima sebagai core curriculum. Core curriculum lebih mirip kepada kurikulum yang mengusahakan integrasi serta menyesuaikan bahan pelajaran dengan kebutuhan murid atau masyarakat. 


\section{F. MENENTUKAN SCOPE DAN SQUENCE DALAM PEMBINAAN KURIKULUM}

Menentukan scope yaitu apa yang harus diajarkan merupakan suatu masalah yang makin lama makin bertambah sulit karena, eksplosi ilmu pengetahuan, belum ada kriteria yang pasti tentang bahan yang akan diajarkan, dan mata pelajaran yang tradisional tidak lagi memadai.

Kurikulum yang dianggap lebih bermakna supaya lebih mudah untuk diingat adalah bila bahan pelajaran dihubungkan atau didasarkan atas pengalaman anak dalam kehidupannya sehari-hari. Yang dijadikan bahan kurikulum bukan hanya disiplin ilmu berupa pengetahuan tetapi juga prosesnya. Selain itu materi atau content pendidikan Islam secara umum dewasa ini lebih cenderung lahir dari persoalan kebutuhan yang seharusnya diberikan kepada siswa. Untuk mengidentifikasi kebutuhan ini, ahli-ahli pendidik menerjemahkan materi atau content dalam bentuk yang lebih konkret. Walker (1981:283) misalnya memberi penekanan makna materi pembelajaran yaitu apa yang seharusnya dapat diajarkan, dipelajari dan dibelajarkan kepada para siswa. Dalam hal ini berupa keperluan-keperluan hidup siswa. ${ }^{8}$

Begitu pula yang perlu dipertimbangkan dalam menyusun kurikulum soal luas dan kedalaman bahan mata pelajaran. Bahan pelajaran umum yang harus dimiliki oeh seluruh warga Negara sedangkan yang khusus diperlukan untuk kepentingan tertentu.

Kriteria penentuan bahan pelajaran ialah: (1) bahan pelajaran harus dipilih berdasarkan tujuan yang hendak dicapai, (2) bahan pelajaran sangat berharga sebagai warga generasi yang lampau, (3) bahan pelajaran berguna untuk menguasai suatu disiplin ilmu, (4) bahan pelajaran dianggap berharga bagi manusia dalam hidupnya, (5) bahan pelajaran sesuai dengan kebutuhan dan minat anak.

Prosedur penentuan bahan pelajaran yaitu: (1) prosedur menerima otoritas para ahli, (2) prosedur eksperimental, (3) prosedur ilmiah atau analis, (4) prosedur konsensus.

Menentukan sequence dalam kurikulum harus diketahui bahwa sequence adalah urutan pengalaman belajar itu diberikan. Ada dua pendekatan dalam penentuan urutan bahan pelajaran yaitu: (1) lebih dahulu menentu-

8 Irpan Abd. Gafar, "Kurikulum Dan Materi Pendidikan Islam." Hunafa: Jurnal Studia Islamika, (LP2M Institut Agama Islam (IAIN) Palu), 3, no. 1 (Maret 2006). Dalam https://www.jurnalhunafa.org/index.php/hunafa/article/view/243/230 
kan bahan pelajaran untuk kelas-kelas tertentu dan (2) menyesuaikan bahan pelajaran dengan taraf perkembangan anak.

Struktur disiplin harus diikuti untuk mempelajarinya dengan langkahlangkah dalam proses belajar.

Faktor-faktor dalam penempatan bahan pelajaran antara lain: (1) taraf kesulitan bahan pelajaran, (2) apersepsi atau pengalaman lampau, (3) kematangan anak, (4) usia mental anak, (5) minat anak.

\section{G. MENGUBAH KURIKULUM}

Kurikulum berubah jika satu atau beberapa asas kurikulum berubah. Perubahan salah satu asas dapat membawa perubahan dalam keseluruhannya. Menilai kurikulum dalam keseluruhannya sangat kompleks karena banyak factor yang mempengaruhi anak.

Untuk menilai kurikulum harus dinilai komponen-komponennya yaitu(1) tujuan, (2) bahan pelajaran, (3) pengalaman dan kegiatan belajar, (4) organisasi kurikulum, (5) cara-cara evaluasi hasil belajar.

Tidak ada satu cara yang pasti untuk menjamin keserasian bahan pelajaran guna mencapai tujuan tertentu.Tujuan matapelajaran yang terlampau luas sukar dinilai. Karena penilaian kurikulum harus dimulai dengan hakikat dan tujuan kurikulum.

Mengubah kurikulum banyak menemui rintangan karena melibatkan banyak manusia yang terikat oleh tradisi dan juga mempunyai vested interest. Dikatakan bahwa perubahan kurikulum berarti perubahan sosial yang berarti pada hakekatnya mengubah manusia dan lembaga-lembaga.

Pada umumnya ada dua prosedur utama dalam perubahan kurikulum, yaitu administrative approach", yaitu yand dimulai dari pihak atasan dan "grass roots approach", yaitu dimulai dari akar .Tiap pendekatan mempunyai kebaikan dan kekurangannya. Administrative approach didukung oleh seluruh aparatur pendidikan, biaya yang cukup, mengerahkan setiap tenaga ahli yang diperlukan dan sebagainya. Dalam "grass roots approach" tidak ada koordinasi, karena bersifat sendiri-sendiri.

\section{H. KESIMPULAN}

Kurikulum senantiasa harus diubah karena perubahan masyarakat akibat kemajuan ilmu pengetahuan dan teknologi. Perubahan kurikulum harus berjalan kontinue agar tidak usang dan ketinggalan zaman. Tiap guru harus 
menentukan tafsirannya sendiri. Karena ada bermacam-macam definisi tentang kurikulum,. Pilihannya itu akan mempengaruhi konsepsinya tentang tugasnya sebagai pendidik. Ia dapat menganut pendirian yang tradisional, yaitu yang berpegang pada kurikulum yang didasarkan atas subjek atau mata pelajaran yang biasanya diberikan secara terpisah-pisah, atau progresif yaitu mempelajari ilmu untuk memecahkan masalah. Perubahan kurikulum sering merupakan suatu reaksi terhadap kurikulum yang ada. Dalam pembaharuan kurikulum hendaknya sebisa mungkin dimanfaatkan kebaikan-kebaikan bentuk-bentuk kurikulum lainnya. 


\section{DAFTAR PUSTAKA}

Basyit, Abdul. "Implementasi Manajemen Mutu Pendidikan Islam." KOORDINAT: Jurnal Komunikasi Antar Perguruan Tinggi Agama Islam (UIN Jakarta) v.17, no. 1 (2018): 187-210.

Gafar, Irpan Abd. "Kurikulum Dan Materi Pendidikan Islam." Hunafa, Jurnal Studia Islamika (LP2M Institut Agama Islam (IAIN) Palu) 3, no. 1 (Maret 2006).

Hasibuan, Lias. Kurikulum Dan Penikiran Pendidikan. Jakarta: Gaung Persada, 2010.

Khoirudin, M. Arif. "Manajemen Kurikulum Dalam Meningkatkan Mutu Pendidikan." Tribakti: Jurnal Pemikiran Islam 24, no. 1 (Januari 2013).

Muhaimin. Pengembangan Kurikulum Pendidikan Islam di Sekolah, Madrasah dan Perguruan Tinggi. Jakarta: PT. Grafindo Persada, 2002.

Mulyasa, E. Kurikulum Tingkat Satuan Pendidikan. Bandung: Remaja Rosdakarya, 2007.

Munir. Kurikulum Berbasis Teknologi Informasi Dan Komunikasi. Bandung: Alfabeta, 2008.

Nasbi, Ibrahim. "Manajemen Kurikulum: Sebuah Kajian Teoritis." Jurnal IDAARAH I, no. 2 (Desember 2017).

Nasution, S. Asas-Asas Kurikulum. Edt.kedua. Jakarta: Bumi Aksara, 2003.

Nugraha, Muhammad Tisna. Manajemen Kurikulum Pembelajaran. Pontianak: STAIN Pontianak Press, 2010.

Nurhalim, Muhammad. "Analisis Perkembangan Kurikulum DI Indonesia." INSANIA: Jurnal Pemikiran ALternatif Pendidikan (FTIK IAIN Purwokerto) 16, no. 3 (September-Desember 2011).

Rusman. Manajemen Kurikulum. II. Jakarta: PT. Raja Grafindo, 2009.

Sanjaya. Kurikulum Dan Pembelajaran Teori \& Praktek KTSP. Jakarta: Kencana, 2009.

Sista, Taufik Rizki. "Implementasi Manajamen Kurikulum Dalam Meningkatkan Mutu Pendidikan." Jurnal Educan 1, no. 1 (Februari 2017).

Sugiana, Aset. "Proses Pengembangan Organisasi Kurikulum Dalam Meningkatkan Pendidikan Di Indonesia." Jurnal Pedagogik (UIN Sunan 
Kalijaga), Juli-Desember 2018.

Walker. "What Curriculum Research?" In Curriculum And Instruction, by Henry A. Giroux et.al. McCutchan USA: Publishing Corporation, 1981.

Yamin, Moh. Panduan Manajemen Mutu Kurikulum Pendidikan, Panduan Lengkap Tata Kelola Kurikulum Efektif. Jogjakarta: DIVA Press, 2012. 